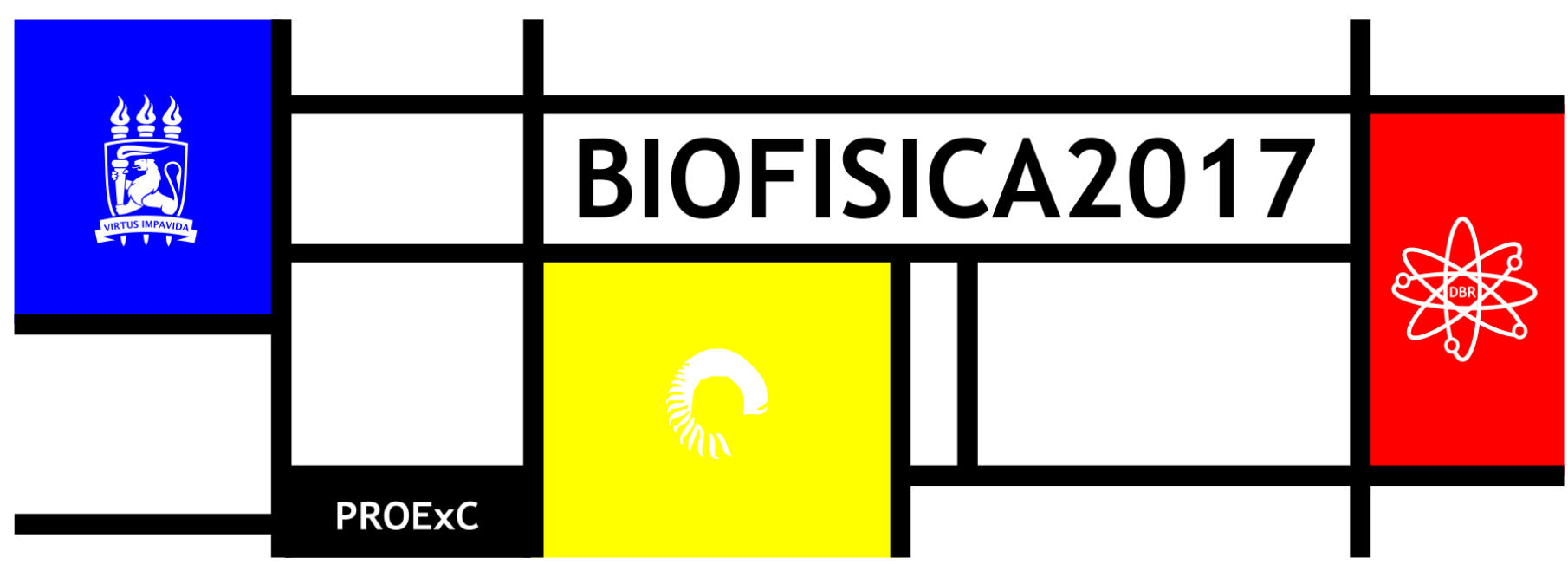

\title{
ASPECTOS MORFOLÓGICOS E MORFOMÉTRICOS DA INTERAÇÃO DE CÉLULAS VERO COM MEMBRANAS DE BIOPOLÍMERO DE CANA-DE-AÇÚCAR
}

\author{
Eduardo Muniz-Filho ${ }^{1 *}$, Laryssa Kathleen Mendonça Ferreira ${ }^{1}$; Erwelly Barros de Oliveira²; João Soares Brito da Luz², \\ Fábio André Brayner dos Santos ${ }^{3}$, Luiz Carlos Alves ${ }^{3}$, José Lamartine de Andrade Aguiar ${ }^{4}$; Eliete Cavalcanti da Silva ${ }^{1}$; \\ Paloma Lys de Medeiros ${ }^{1,2}$ \\ 'Laboratório de Cultura de Tecido do Dept ${ }^{\circ}$. de Histologia e Embriologia (LCT-DHE/UFPE); ${ }^{2}$ Programa de Pós-graduação em Inovação Terapêutica \\ (PPGIT/UFPE), ${ }^{3}$ Setor de Microscopia Eletrônica - Laboratório de Imunopatologia Keizo Azami (LIKA/UFPE); ${ }^{4}$ Programa de Pós-graduação em \\ Cirurgia do Hospital das Clínicas-CCS/UFPE \\ *munizef22@gmail.com
}

\section{INTRODUÇÃO}

A cultura de células, base de muitas pesquisas voltadas para a terapia celular e a engenharia tecidual, constitui uma área promissora da ciência que envolve segmentos como biologia celular, bioengenharia, biomateriais, bioquímica e biofísica, que tem como objetivo a reconstrução de tecidos ou órgãos corporais que perderam sua funcionalidade (PERTILE et al., 2007; BOROJEVIK, 2008; PLACE; EVANS; STEVENS, 2009). Neste contexto, deve-se levar em conta também, que modelos de cultura celular estão se tornando prevalentes na investigação da reação dos tecidos a materiais de implantes e que o uso de métodos in vitro pode reduzir a extensão de testes em animais e diminuir significativamente o tempo e o custo das análises de uma forma geral (CARVALHO et al., 2010; PRESGRAVE, et. al., 2010; BASKETTER et al., 2012; VICTAL et al., 2014).

Um grupo de células bastante importante no processo de regeneração de tecidos são os fibroblastos, que atuam remodelando-os e produzindo vários componentes de matriz extracelular, como o colágeno; assim como, fatores de crescimento que controlam a proliferação e diferenciação celular (JUNQUEIRA; CARNEIRO, 2013). A célula Vero (uma linhagem fibroblastóide de rim do macaco verde africano, Cercopithecus aethiops) tem sido escolhida como modelo para testes de citotoxicidade e adesão a biomateriais. Estas representam um padrão internacional para estudos com Biomateriais (KIRKPATRICK, 1992); o que reforça a utilização das mesmas em nossa pesquisa.

Os biopolímeros despontam como ferramentas inovadoras, em função da sua biocompatibilidade e o biopolímero de cana-deaçúcar, um exopolissacarídeo produzido a partir da fermentação do melaço pela bactéria Zoogloea sp., vem sendo utilizado em diversas aplicações nas áreas das Ciências da Saúde e da Biologia (PATERSON-BEEDLE et al., 2000; CASTRO, et al., 2004; AGUIAR et al., 2007; CAVALCANTE, et al., 2007; SILVEIRA et al., 2007; MAYER et al., 2011; MARTINS et al., 2013; SILVEIRA et al., 2014; ABREU et al., 2016).
Logo, o objetivo do nosso estudo foi avaliar in vitro os aspectos morfológicos e morfométricos da interação de células Vero com membranas de biopolímeros de cana-de-açúcar.

\section{MATERIAIS E MÉTODOS}

Os experimentos foram realizados no Laboratório de Cultura de Tecidos do Departamento de Histologia e Embriologia (LCT-DHE) e as membranas de biopolímero de cana-de-açúcar foram gentilmente cedidas pelo grupo de pesquisa Biopolímeros de Canade-Açúcar, coordenado pelo Prof. Dr. José Lamartine de Andrade Aguiar, do Programa de Pós-graduação em Cirurgia do Hospital das Clínicas-CCS/UFPE.

As Células Vero, linhagem proveniente do rim do macaco verde africano (Cercopithecus aethiops), vem sendo mantida em cultura no Laboratório de Cultura de Tecidos (LTC-DHE). Parte dessas células, também, encontra-se congelada (armazenadas para preservação da linhagem). As células Vero são recomendadas para estudos de citotoxicidade e para interações célula-substrato com biomateriais (XUE; GREISLER, 2003).

No início dos ensaios as células foram descongeladas em banhomaria e posteriormente, centrifugadas sob refrigeração. 0 pellet celular formado foi ressuspendido em meio DMEM suplementado com $10 \%$ de soro fetal bovino e mistura de antibióticos $(100 \mathrm{Ul} / \mathrm{mL}$ de penicilina e $100 \mu \mathrm{m} / \mathrm{mL}$ de estreptomicina, Sigma ${ }^{\oplus}$ ). As células foram cultivadas e mantidas em estufa com $5 \%$ de $\mathrm{CO}_{2}$, a $37^{\circ} \mathrm{C}$ e 85 $\%$ de umidade controlada.

As células Vero cultivadas sobre as membranas porosas do biopolímero de cana-de-açúcar foram avaliadas em microscópio invertido com contraste de fase (LEICA) acoplado com câmera digital (MOTICAM 2.000 de 1,2 Mega Pixel), em uma magnitude final de 100X. Fotografias digitais foram realizadas utilizando-se o software Motic Images Plus 2.0 ML. As imagens obtidas foram analisadas com o auxílio de um software NIH ImageJ 1.36b (National Institutes of Health, Maryland, EUA), para determinação da contagem de células. Foram capturados 15 campos por garrafa no período de 24 , 48 e 72 horas de cultivo, definindo-se uma área 
para contagem das células de $90.000 \mu \mathrm{m} 2$, tanto sobre a superfície da biomembrana como no interior dos poros (área em contato com o plástico da garrafa). Foram selecionados 07 campos, correspondentes as melhores imagens, para realização das contagens e análise estatística dos dados coletados.

Parte das células juntamente com o biosuporte, foi processada para a microscopia eletrônica de varredura (MEV). As células foram fixadas em solução de $0,5 \mathrm{~mL}$ de glutaraldeído e $4,5 \mathrm{~mL}$ de solução tampão $(\mathrm{pH}=7,4) \mathrm{e}$, em seguida, preparadas de acordo com protocolo do Setor de Microscopia Eletrônica do Laboratório de Imunopatologia Keizo Azami (LIKA), sob a coordenação de pesquisadores da área.

\section{RESULTADOS E DISCUSSÃO}

Decorrido um período de 24 horas de cultivo (Figura 1A), as células Vero apresentaram-se com aspecto arredondado sobre as membranas e nas áreas correspondente aos poros (em contato com o plástico da garrafa de cultura). Foi possível observar a formação de monocamada com $48 \mathrm{~h}$ da cultura inicial, com um número significativo de células arredondadas e fibroblastóides em ambas as regiões e de característica mais agrupada sobre a membrana (Figura 1B). A confluência celular de aproximadamente $80 \%$ foi observada, em ambas as regiões já referidas inicialmente (Figura 1C). Nossos resultados corroboram com a caracterização morfológica mencionada na literatura, onde os fibroblastos são descritos como células de regeneração com tendência a crescerem rapidamente (JUNQUEIRA; CARNEIRO, 2013).

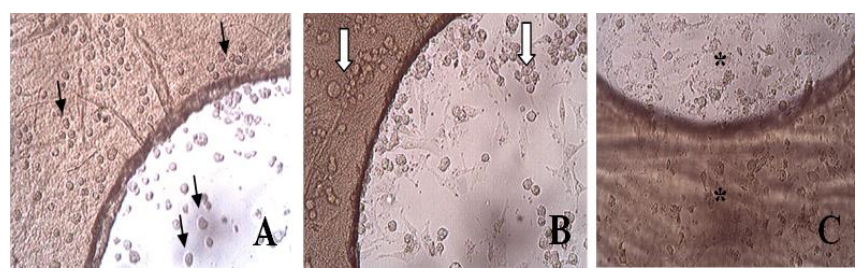

Figura 1. Fotomicrografias da cultura de células Vero em garrafas de cultura revestidas com membranas porosas do Biopolímero de cana-de-açúcar, registradas com microscópio invertido com contraste de fase: A) Células com forma arredondada (setas finas) no início da cultura (24 horas). B) Células fibroblastóides na região do poro e de forma agrupada (setas cheias brancas) sobre a membrana (48 horas) e C) Células confluentes (asteriscos) em ambas as regiões, aparentemente mais espalhadas dentro do poro e com densidade reduzida sobre a membrana (72 horas de cultivo). Magnitude: 100X (A, B, C).

As culturas foram acompanhadas por um período de aproximadamente uma semana e foi possível observar células com aspecto fibroblastóides aderidas às regiões do poro (em contato com o plástico) e sobre a membrana do biopolímero, especialmente em áreas com presença de dobras no referido biomaterial (Figura 2). A adesão dessas células às biomembranas revela um dos principais requisitos referidos por Pertile e colaboradores (2007), direcionado a um biomaterial com capacidade de formar ligações sólidas e biocompatíveis com as células, proporcionando a interação de proteínas de membrana celular com o biosuporte.

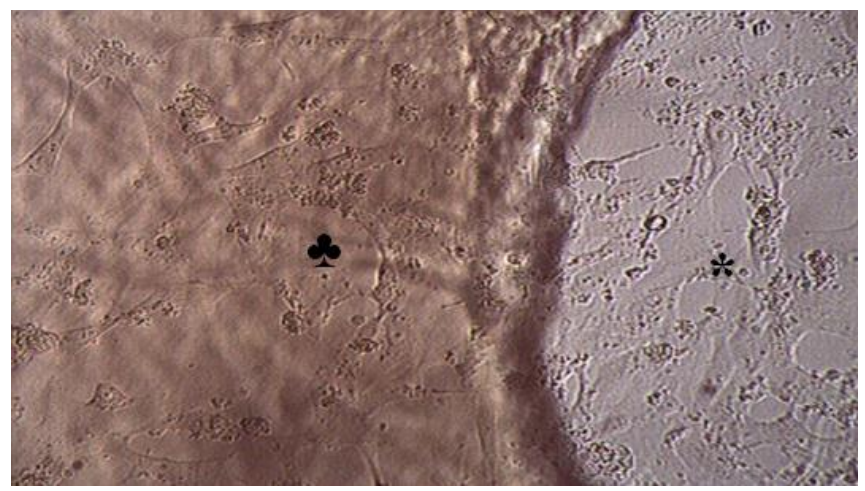

Figura 2: Fotomicrografia da cultura de células Vero em garrafas de cultura revestidas com membranas porosas do Biopolímero de cana-de-açúcar por um período de uma semana, registradas com microscópio invertido com contraste de fase. Observam-se células fibroblastóides de aspecto confluente (asterisco) na região do poro (em contato com o plástico da garrafa) e sobre dobras da membrana (trevo) de forma mais dispersa. Magnitude: 100x.
A figura 3 representa o número de células/área $\left(\mu \mathrm{m}^{2}\right)$ obtido a partir da análise de 07 campos/garrafa de cultura com 24,48 e 72 horas de cultivo. Nossos resultados demonstram um aumento rápido do número de células sobre a membrana e dentro dos poros com 48 horas de observação da cultura, corroborando com uma das características típicas dos fibroblastos, consideradas como células de regeneração e com tendência a crescimento rápido e isto foi visualizado no gráfico. Todavia, com 72 horas, observou-se uma redução não significativa $(p<0,05)$ do número de células em ambas as regiões avaliadas. Morfologicamente, as células apresentam-se mais delgadas, tendem a um aspecto fusiforme, e apresentam-se metabolicamente quiescentes (JUNQUEIRA; CARNEIRO, 2013).

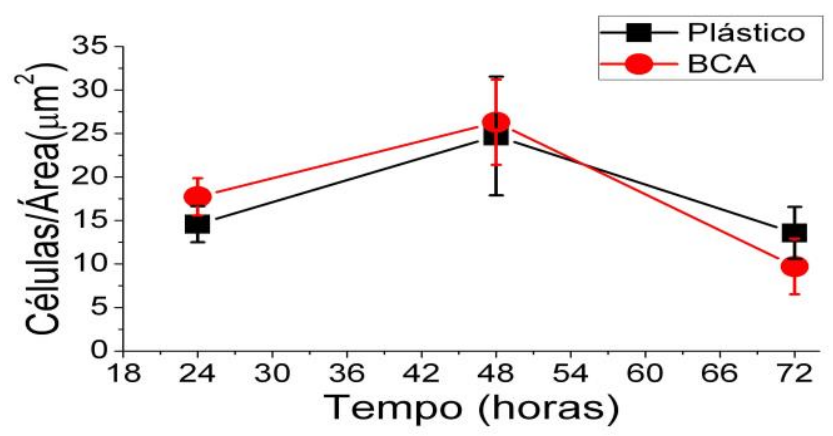

Figura 3: Compatibilidade das células Vero com membranas do biopolímero de cana-deaçúcar no período de 24,48 e 72 horas de cultura. Nota-se nítido aumento do número de células com 48 horas do cultivo inicial, sobre o biopolímero (BCA) e nas regiões referentes aos poros (Plástico), todavia não significativo. Os dados foram analisados com o teste ANOVA, seguido pelo pós-teste de comparações múltiplas de Tukey $(p>0,05)$ e expressos como média e desvio padrão ( $\mathrm{n}=07$ campos/garrafas).

A avaliação da interação das células-tronco mesenquimais com o biomaterial por meio da microscopia eletrônica de varredura revelou variados formatos das células Vero, desde as formas arredondadas até aquelas com aspecto irregular (Figura 4). Observamos que a estrutura da malha do biopolímero de cana-deaçúcar foi é capaz de permitir a ancoragem das células Vero e mediar a comunicação com células adjacentes. Segundo Santos (2007), o processo de adesão celular é um fator relevante para que seja possível a proliferação celular sobre o biomaterial, corroborando com os resultados encontrados.
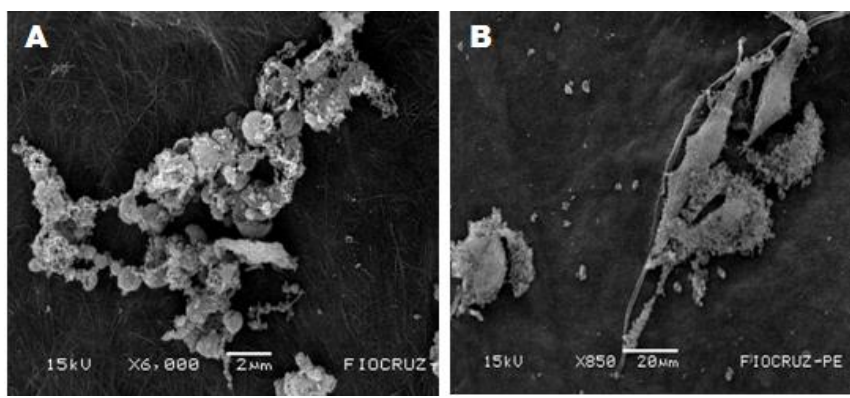

Figura 4. Microscopia eletrônica de varredura de células Vero cultivadas sobre membranas de biopolímero de cana-de-açúcar. Observou-se a interação das células Vero com o biosuporte através da ancoragem das mesmas às fibras do biomaterial ( $A$ e $B$ ). As células apresentaram-se com formas arredondadas e agrupadas (A) e fibroblastóides (B). Escalas de barra $=2 \mu \mathrm{m}(\mathrm{A})$ e $20 \mu \mathrm{m}$ (B).

Deve-se levar em conta também, que modelos de cultura celular estão se tornando prevalentes na investigação das respostas dos tecidos aos diferentes tipos de implantes (VERRIER et al., 1996). 0 uso de métodos in vitro pode reduzir a extensão de testes em animais e pode diminuir, significativamente, de uma forma geral o tempo e o custo das análises (PRESGRAVE, et. Al., 2010; BASKETTER et al., 2012; SÀNDOR, 2013; VICTAL et al., 2014).

Segundo Barros (2013), o biopolímero de cana-de-açúcar demonstrou-se ser um suporte adequado para o cultivo de célulastronco mesenquimais, que também se caracterizam como células com aspecto fibroblastóide, e foi capaz de sustentar o crescimento das mesmas, favorecendo a remodelação citoplasmática, assim 
como proporcionando um ambiente adequado para a diferenciação dessas células em queratinócitos (ARAÚJO et al., 2014).

\section{CONCLUSÕES}

As células Vero apresentaram-se metabolicamente mais ativas quando cultivadas sobre as membranas do biopolímero de cana-deaçúcar (BCA), o que refletiu em modificações de sua morfologia. Com 48 horas do cultivo inicial, considerável número de células fibroblastóides foi visualizado nas regiões referentes aos poros do BCA, sendo as formas arredondadas e agrupadas mais evidentes sobre as biomembranas.

As biomembranas mostraram-se biocompatíveis e foram capazes de proporcionar a adesividade das células Vero independente do período de observação.

\section{REFERÊNCIAS}

ABREU, T. C.; LIMA, R. P.; SOUZA, V. S. B.; CAMPOS-JÚNIOR, O.; ALBUQUERQUE, A. V.; AGUIAR, J. L. A.; ANDRADE, E. S. S.; VASCONCELOS, B. C. E. The polymer sugarcane as filling material of critical defects in rats. Acta Cirúrgica Brasileira; Rio de Janeiro, v. 31, n. 1, p. 53-58, 2016.

AGUIAR, J. L. A.; LINS, E. M.; MARQUES, S. R. B.; COELHO, A. R. B.; ROSSITER, R. O.; MELO, R. J. V. Sugarcane biopolymer patch in femoral artery angioplasty on dogs. Acta Cirúrgica Brasileira; Rio de Janeiro, v. 22, p. 77-81, 2007.

ARAÚJO, P. H. C.; DIAS, M. R. P.; AGUIAR, J. L. A.; SILVA, M. B.; SILVA, E. C.; MEDEIROS, P. L. 2014. Diferenciação de células-tronco mesenquimais de cordão umbilical humano em queratinócitos sobre biomembranas de cana-de-açúcar. Revista Enfermagem Atual In Derme, Rio de Janeiro, v. 68, n. 6, p. 18-21, 2014.

BARROS, L. A. Aspectos morfofuncionais de células-tronco mesenquimais do cordão umbilical humano cultivadas sobre matrizes tridimensionais de biopolímero de cana-de-açúcar, Dissertação de mestrado. Programa de Pós-graduação em Inovação Terapêutica da UFPE, pp. 76, 2013.

BASKETTER, D. A., CLEWELL, H., KIMBER, I. A road-map for the development of alternative (non-animal) methods for systemic toxicity testing-t4 report. ALTEX, v. 29, p. 3-91, 2012.

BOROJEVIC, R. Terapias Celulares e Bioengenharia. Gazeta Médica da Bahia, Bahia, v. 78, n.1, p. 4246, 2008.

CARVAlHO, A. C. A.; PEREIRA, E. S. C.; COSTA, C.; BARRETO, I. C.; MADUREIRA, L. C.; PAIM, F. R. Estratégias regenerativas da bioengenharia tecidual e aspectos éticos. Revista das Ciências Médicas e Biológicas, Bahia, v. 9, p. 20-27, 2010.

CASTRO, C. M. M. B.; AGUIAR, J. L. A.; MELO, F. A. D.; SILVA, W. T. F.; MARQUES, E.; SILVA, D. B. 2004. Citotoxicidade de biopolímero de cana-de-açúcar. Anais da Faculdade de Medicina da Universidade Federal de Pernambuco, Pernambuco, v. 49, n.2, p. 119-123, 2004.

CAVAlCANTE, A. H. M., CARVAlho, J. L. B., CARNEIRO-CUNHA, M. G. Journal of Biochemical Engineering, v. 29, p. 258-261, 2007. GRANJEIRO, J. M. Papel dos biomateriais e da bioengenharia na medicina regenerativa. Innovations Implant Journal: Biomaterials and Esthetics, v. 1, n. 2, 16-27, 2007.

JUNQUEIRA, L. C.; CARNEIRO, J. Histologia Básica - Texto e Atlas 2013. 12 ${ }^{a}$ Ed. Rio de Janeiro: Guanabara Koogan, pp. 538.

KIRKPATRICK, C. J. Biological testing of materials and medical devices - A critical view of current and proposed methodologies for biocompatibility testing: cytotoxicity in vitro. Regulatory Affairs, v. 4, n. 1, p. 13-32, 1992.

KUMARI, T. V.; VASUDEV, U.; KUMAR, A.; MENON, B. Cell surface interactions in the study of biocompatibility. Trends in biomaterials and artificial organs, v. 15, n. 2, p. 37-41, 2002.

MADLA, S.; MIETHACONONE, P.; PRASITSILB, M.; KIRTIKARA, K. Characterization of fungi-derived polymers that are biocompatible and inducers IL-8 production. Carbohydrate Polymers, v. 59, p. 275-280, 2005.
MAGER, M. D.; LA POINTE. V.; STEVENS, M. M. Exploring and exploiting chemistry at the cell surface. Nature, v. 3, p. 582-589, 2011.

MARTINS, A. G. S.; CORREIA LIMA, S. V.; ARAÚJO, L. A. P.; VILAR, F. O.; CAVALCANTE, N. T. P. A wet dressing for hypospadias surgery. International Brazilian Journal of Urology, v. 39, n. 3, p. 408-413, 2013.

MAYER, D. L. B.; ARAÚJO, J. G.; LEAL, M. C.; CALDAS NETO, S. S.; ATAÍDE, R. F.; MELLO, R. J. V. 2011. Membrana do biopolímero da cana-de-açúcar: avaliação experimental na orelha média. Brazilian Journal of Otorhinolaryngology, v. 77, n. 1, p. 44-50, 2011.

PATTERSON-BEEDLE, M. KENNEDY, J. F.; MELO, F. A. D.; LLOYD, L. L.; MEDEIROS, V. A cellulosic exopolysaccharide produced from sugarcane molasses by a Zoogloea sp. Carbohydrate Polymers, v. 42, n.4, p. 375-383, 2000.

PÉRTILE, R. A. N., SIQUEIRA JR, J. M., RAMBO, C. R., BERTI, F. V., DO VALLE, R. M. R., PORTO, L. M. Interação de culturas celulares com suportes biopoliméricos para aplicações biomédicas. Exacta, São Paulo, v. 5, n. 2, p. 343-352, 2007.

PLACE, E. S.; EVANS, N. D.; STEVENS, M. M. Complexity in biomaterials for tissue engineering. Nature Biomaterials, v. 8, p. 457-470, 2009.

PRESGRAVE, O. A. F. et al. A Proposal to establish a Brazilian Center for Validation of Alternative Methods (BraCVAM). Altex, v. 27, p.47-51, 2010.

SÀNDOR, G. K. Tissue engineering: Wave of change. Annals of Maxillofacial Surgery, v. 3, n. 1, p. 1-2, 2013.

SANTOS JR, A. R.; WADA, M. L. F. Polímeros biorreabsorvíveis como substrato para cultura de células e engenharia tecidual. Polímeros: Ciência e Tecnologia, v. 17, n. 4, p. 308-317, 2007.

SILVA, D. B.; AGUIAR, J. L. A.; MARQUES, A.; COELHO, A. R. B.; ROLIM FILHO, E. L. Miringoplastia com enxerto livre de membrana de biopolímero de cana-de-açúcar e fascia autóloga em Chinchilla laniger. Anais da Faculdade de Medicina da Universidade Federal de Pernambuco, v. 51, n. 1, p. 45-51, 2006.

SILVEIRA, A. A.; DANTAS, M. L. M.; ALMEIDA, Y. M. B.; AGUIAR, J. L. A. Estudo biomecânico de membranas de biopolímero de canade-açúcar perfuradas e contínuas implantadas no celular subcutâneo da parede abdominal de ratos. Anais da Faculdade de Medicina da Universidade Federal de Pernambuco. v. 52, n.1, p. 55-59, 2007.

SILVEIRA, A. B. F. N.; AGUIAR, J. L. A.; CAMPOS JÚNIOR, O.; DINIZ, G. T.; CORREIA LIMA, S. V. 2014. Biopolymer membrane of sugarcane: a reality as an option for the correction of urinary incontinence. Millenium, Portugal, v. 46, 81-95, 2014.

VICTAL, J. C.; VALÉRIO, L. B.; OSHIRO, M. C.; BAPTISTA, S. C.; PINHEIRO, F. Métodos alternativos in vitro e in silico: métodos auxiliares e substitutivos à experimentação animal. RevInter Revista Intertox de Toxicologia, Risco Ambiental e Sociedade, v. 7, n. 2, p. 36-57, 2014.

XUE, L.; GREISLER, H.P. Biomaterials in the development and future of vascular grafts. Journal of Vascular Surgery, v. 37, p. 472-480, 2003.

\section{APOIO}

Propesq (UFPE) e CNPq 